\title{
Habitação e políticas públicas: o que se tem pesquisado a respeito?
}

Housing and public policy: what has been researched about it?

Lucas Pazolini Dias Rodrigues, Vinícius de Souza Moreira

Universidade Federal de Viçosa (UFV), Viçosa, MG, Brasil

\section{Resumo}

Objetivou-se com este artigo analisar a produção científica sobre a política habitacional brasileira, a partir de 1964 até 2014, de forma a compreender como essa questão tem sido estudada pela Administração e por outras áreas das Ciências Sociais Aplicadas. Para tanto, realizou-se um metaestudo, que foi sistematizado em três momentos: (i) a escolha da literatura a ser analisada; (ii) o levantamento das informações; (iii) a análise, a interpretação e a apresentação dos resultados. A técnica de análise de conteúdo, subdivida nas etapas de pré-análise, exploração do material e tratamento dos resultados, deu suporte à construção da proposta. Alguns resultados interessantes foram: predomínio dos pesquisadores gaúchos e paulistas, pertencentes, principalmente, à Universidade Federal do Rio Grande do Sul e Universidade de São Paulo; o emprego de pesquisas de cunho avaliativo que envolviam programas habitacionais de abrangência nacional, como o Programa Minha Casa, Minha Vida e o Programa de Arrendamento Residencial, executados a nível local. No entanto, algumas lacunas foram identificadas: o direcionamento de estudos à provisão habitacional, isto é, à construção de casas, com pouca produção envolvendo outras perspectivas da política de habitação, como a reforma e a regularização de assentamentos precários; o predomínio das pesquisas em âmbito urbano indicando a carência de estudos direcionados à habitação rural.

Palavras-chave: Habitação. Políticas públicas. Metaestudo.

\section{Abstract}

Objective with this article to review scientific literature on the Brazilian housing policy, from 1964 to 2014 in order to understand how this issue has been studied by management and other areas of Applied Social Sciences. Therefore, we performed a meta-study that was systematized in three stages: (i) selection of literature to be analyzed; (ii) collecting the information and (iii) the analysis, interpretation and presentation of results. The content analysis technique, subdivide the steps of pre-analysis, material exploration and treatment of results supported the construction of the proposal. Some interesting results: predominance of the gauchos and São Paulo researchers, belonging mainly to the Federal University of Rio Grande do Sul and São Paulo University; and the use of evaluative nature of research involving housing programs nationwide, as the Minha

LPDR é mestrando em Administração, e-mail: lucas.pazolini@ufv.br VSM é mestrando em Administraç̃ão, e-mail: vinicius.souza@ufv.br 
Casa, Minha Vida and the Residential Leasing Program implemented at local level. On the other hand, certain shortcomings were identified: the direction of studies on housing provision, that is, building houses with little production involving other perspectives of housing policy, as the reform and regularization of slums; and the predominance of research in urban context indicating the lack of research focusing on rural housing.

Keywords: Housing. Public policy. Meta-study.

\section{Introdução}

0 processo de formação e de urbanização das cidades brasileiras acentuou as desigualdades sociais, inclusive no que tange ao acesso à moradia (Maricato, 2008) que atenda aos mínimos padrões de habitabilidade. Com isso, o governo percebeu essa situação como relevante para compor seu escopo de atuação. A primeira política pública estruturada para enfrentamento do problema habitacional formalizou-se em $1964 \mathrm{com}$ o Sistema Financeiro da Habitação (SFH) e o Banco Nacional da Habitação (BNH). Todavia, o BNH atuou durante 22 anos e foi extinto em 1986, provocando um "esvaziamento" da intervenção governamental entre 1987 e 1999.

A partir dos anos de 2000, pôde-se perceber a retomada de ação do governo na questão, com destaques para eventos importantes, tais como: a inclusão da moradia como direito social na Constituição Brasileira em 2000; a promulgação do Estatuto das Cidades no ano de 2001, que trouxe a afirmação da função social da propriedade; a criação, em 2003, do Ministério das Cidades; o estabelecimento da Política Nacional de Habitação e do Plano Nacional de Habitação em 2004 e 2007, respectivamente.

É possível perceber, por meio dessa descrição histórica, três momentos distintos demonstrando a intensidade da atuação governamental: 1964-1986; 1987-1999; 2000-2014. Tais períodos servirão como elementos temporais norteadores do estudo, tendo em vista a sua possível influência na produção científica nacional.

No primeiro período destacado (1964 a 1986), tem-se o início da atuação massiva estatal quanto ao problema habitacional, o que possibilitou a criação de mecanismos de financiamento e de implementação, como o Fundo de Garantia por Tempo de Serviço (FGTS) e as Companhias de Habitação (COHABs), que subsidiaram as políticas habitacionais dos períodos posteriores. Nesse sentido, pretendeu-se verificar como as primeiras publicações relacionavam essa situação-problema e a atuação governamental.

O segundo período (1987 a 1999), por apresentar forte declínio da intervenção do Estado na temática, possui importante relevância para se compreender o comportamento da produção científica - se houve a indução ou a dissuasão para a realização de estudos.

Por fim, entretanto não menos importante, destaca-se o terceiro período (2000 a 2014), no qual há a retomada das ações estatais, com a instituição de novas políticas e programas.

0 presente artigo teve como foco central a produção acadêmica da área de Administração, com a abertura de espaço às outras áreas das Ciências Sociais Aplicadas, desde que trouxessem em seu escopo a inter-relação entre habitação e políticas públicas. Com isso, considerou-se pertinente a seguinte questão de pesquisa: o que se tem produzido a respeito da política habitacional brasileira?

Como forma de auxiliar na composição do panorama da produção científica pretendida e responder ao questionamento citado, utilizou-se o modelo do ciclo de políticas públicas (policy cycle) como um de seus elementos delineadores. A escolha do policy cycle vai ao encontro da análise de políticas públicas. Como a proposta do artigo é analisar a produção que versa sobre a habitação e as políticas públicas, considerou-se pertinente trazer essa perspectiva teórico-analítica para a análise aqui desenvolvida.

O primeiro modelo que considerava a formação e o desenvolvimento das políticas públicas por meio de etapas sequenciais foi proposto no início da década de 1950 pelo cientista político Harold Laswell. A partir dos seus estudos, foram realizadas variadas concepções quanto aos estágios do ciclo de políticas públicas (Theodoulou, 1995; Frey, 2000; Saravia, 2006; Rua, 2009; Secchi, 2010). Para os fins deste artigo, foram adotados como base os estágios propostos por Frey (2000): percepção do problema, definição de agenda, formulação de política, implementação e avaliação. 
Destacados os aspectos relevantes, apresenta-se o seu objetivo geral: analisar a produção científica sobre a política habitacional brasileira, de forma a compreender como essa questão tem sido estudada pela Administração e por outros campos do conhecimento que abrangem às Ciências Sociais Aplicadas. Assim, pretende-se compor o cenário das publicações científicas, identificando as principais temáticas abordadas, o foco e os objetos de estudo, assim como questões relacionadas às técnicas de coleta e de análise mais utilizadas.

Além desta seção introdutória, o artigo é composto por outras três. Na seção seguinte, expõem-se, de forma detalhada, os procedimentos metodológicos que possibilitaram a realização das coletas de dados e a condução das análises. Em seguida, são apresentados os principais resultados encontrados e, por fim, os comentários finais.

\section{Procedimentos metodológicos}

\section{Características da pesquisa}

De forma a analisar o que tem sido produzido a respeito da temática habitacional e seu entrelaçamento com as políticas públicas, realizou-se um estudo de caráter exploratório e descritivo. A proposta é, justamente, explorar e detalhar a produção científica que abrange o tema aqui pesquisado.

Valendo-se dessas características, optou-se pela utilização do metaestudo, técnica, segundo Rich et al. (1999), amplamente difundida e reconhecida. Tais autores argumentam que a finalidade é a acumulação de resultados a partir de outros estudos, tendo a perspectiva de construir um panorama mais apurado do relacionamento das pesquisas, em detrimento dos achados individuais de cada estudo.

Oliveira (1996) preconiza que estudos dessa natureza trazem importantes indagações sobre os procedimentos metodológicos adotados, as principais correntes teóricas e o alcance e limitações dos enfoques utilizados. Wood \& Chueke (2008) complementam que a relevância dos metaestudos repousa no fato de proporcionarem à comunidade acadêmica a possibilidade de situar-se a respeito do que está sendo produzido sobre determinado assunto.

Destaca-se que estudos com o intuito de analisar a produção científica habitacional no Brasil têm sido desenvolvidos por outros pesquisadores, tais como Abreu (2012), Mororó et al. (2012) e Nascimento \& Moreira (2014).

\section{Operacionalização da pesquisa}

A operacionalização do metaestudo baseia-se na sistematização de um conjunto de dados obtidos a partir da literatura científica pesquisada. Inicia-se com a (i) escolha da literatura a ser analisada, partindo para o (ii) levantamento das informações descritas no material bibliográfico e finalizando com a (iii) análise, a interpretação e a apresentação dos resultados (Cooper \& Lindsay, 1998; Brito \& Berardi, 2010).

A escolha da literatura justifica-se pela importância da temática habitacional como problema de políticas públicas (Azevedo, 1988; Melo, 1993; Arretche, 1996; Bonduki, 2004; Maricato, 2008). Assim, realizou-se a busca de artigos científicos e de ensaios teóricos que envolvessem os temas "habitação" e "políticas públicas" em periódicos incluídos no sistema classificatório WebQualis da Coordenação de Aperfeiçoamento de Pessoal de Nível Superior (CAPES) com avaliação A1, A2, B1 e B2. Os estratos de avaliação são referentes às áreas de Administração, Ciências Contábeis e Turismo, e as buscas ocorreram em duas bibliotecas eletrônicas: na Scientific Electronic Library Online (SciELO) e na Scientific Periodicals Electronic Library (SPELL).

Haja vista a demarcação do campo de manifestação científica apresentada e a temática habitacional como objeto de políticas públicas para o desenvolvimento científico, ressalta-se a ausência de produções relevantes como livros, teses, dissertações, monografias e periódicos.

A seleção dos textos tinha o intuito de abranger os principais momentos da trajetória da ação governamental diante do quadro habitacional do país, compreendendo o período de 1964 até 2014, conforme ilustrado na Figura 1.

A análise e a interpretação dos resultados basearam-se na análise de conteúdo, uma vez que permite a utilização de procedimentos sistemáticos e objetivos para a descrição do conteúdo de mensagens (Bardin, 2009) em suas mais variadas formas de apresentação.

Adotaram-se as etapas indicadas por Bardin (2009) e Dellagnelo \& Silva (2005), que compreendem a 
pré-análise, a exploração do material e o tratamento dos resultados, inferência e interpretação.

A pré-análise correspondeu à identificação e à reunião de todo o material pesquisado. A pesquisa de artigos teve como norte dois temas centrais que deveriam estar constantes no título dos estudos: "habitação" e "política habitacional".

Nesse sentido, foram encontrados 222 artigos. Após a leitura cuidadosa dos resumos e a realização de uma revisão em toda a estrutura do texto - de modo a encontrar algum tópico relacionado com o objeto de estudo -, foram selecionados 38 artigos. Com essa vistoria inicial, foi possível admitir algumas variações dos termos-chave, uma vez verificada a aderência deles à temática proposta pelo metaestudo.

Para o termo "habitação", as variações admitidas foram: habitações, habitacional, habitar, habitabilidade, moradia, casa e casas. Para "política habitacional", foram admitidos também: políticas habitacionais e política de habitação.

De posse dos artigos, procedeu-se à exploração do material, isto é, fez-se a leitura completa dos textos para validar o ajustamento ao assunto e também como forma de subsidiar a realização das análises.
Assim, as duas etapas iniciais conduziram ao tratamento dos resultados por meio de técnicas de categorização e quantificação. Ressalta-se que o percurso analítico adotado foi inspirado nos estudos de Lage \& Emmendoerfer (2010) e Morais et al. (2013), observadas as modificações particulares para adequação à temática desta pesquisa peculiar.

A investigação teve como elemento norteador as seguintes categorias analíticas: (i) o perfil da publicação; (ii) o foco; (iii) a temática; (iv) a abrangência; (v) as etapas do ciclo de políticas públicas; (vi) o perfil metodológico.

No que se refere ao perfil da publicação, atentouse em identificar os autores, bem como as instituições das quais fazem parte, além do periódico, do ano em que o texto foi publicado e a abrangência do estudo (municipal, estadual, federal).

O foco representa o principal assunto tratado no texto, podendo enfocar a Política Nacional de Habitação e/ou algum programa federal derivado, a política de habitação específica de algum Estado ou município, assim como determinado programa estadual ou municipal específico (Figura 2).

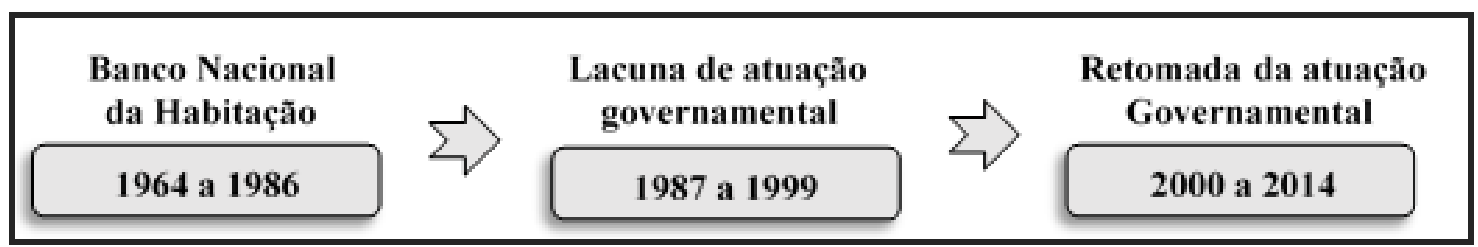

Figura 1 - Trajetória da atuação governamental na questão habitacional Fonte: Elaborada pelos autores.

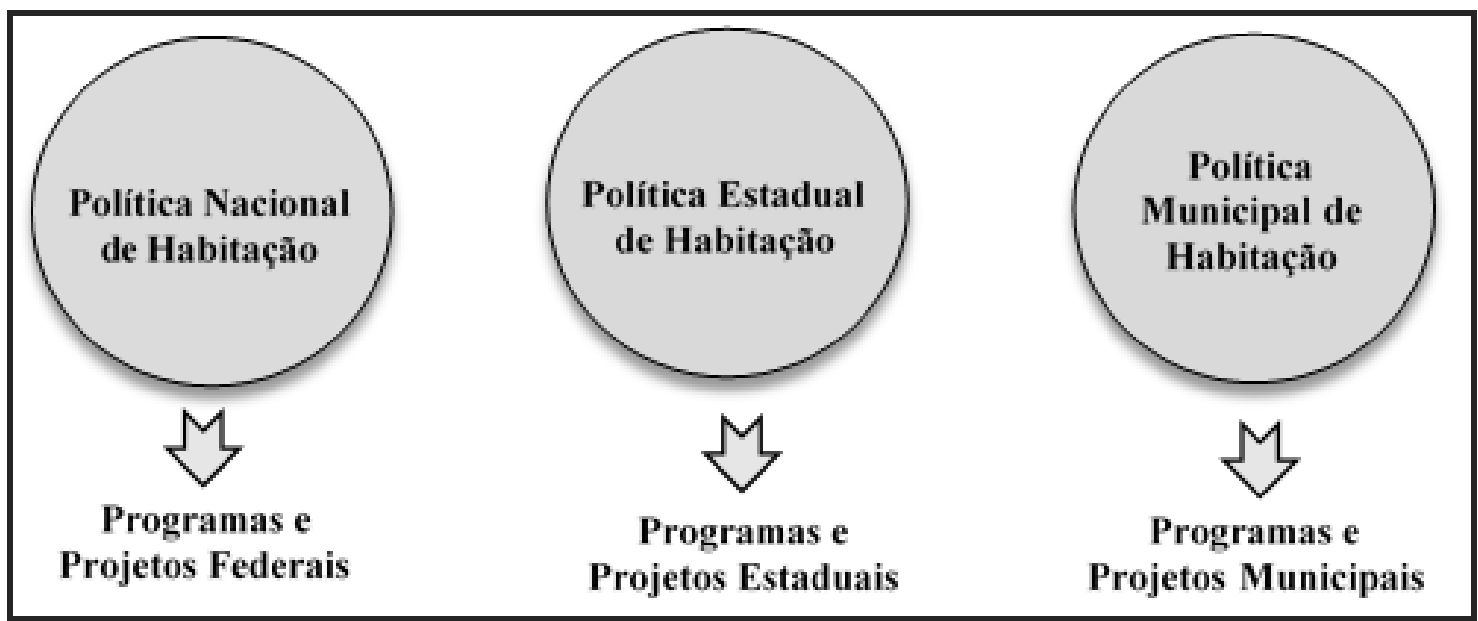

Figura 2 - Principais focos dos estudos

Fonte: Elaborada pelos autores. 
Delimitado o foco, verificou-se também a temática. Para essa etapa, buscou-se averiguar quais os principais temas discutidos nos textos, seja no âmbito da política (nacional, estadual ou municipal), seja no escopo de um programa específico.

As etapas do ciclo de políticas públicas foram utilizadas como categoria de análise, pois tal modelo tem a potencialidade de promover o entendimento das políticas em fases sequenciais, o que facilita o processo de análise (Quadro 1). As etapas consideradas foram: percepção do problema, agenda, formulação, implementação e avaliação (Frey, 2000). A separação em etapas é frequentemente utilizada como referência nas investigações para estudos que envolvem a análise de políticas públicas.

Por fim, para análise do perfil metodológico, fez-se uso das características dispostas no Quadro 2.

Para complementar a exposição dos resultados, recorreu-se à distribuição de frequências, técnica que permite agrupar os dados em classes, de modo a fornecer a quantidade (e/ou a percentagem) de dados em cada classe (Triola, 2005).

Quadro 1 - Etapas do ciclo de políticas públicas

\begin{tabular}{|c|c|}
\hline Etapas & Descrição \\
\hline Percepção do problema & $\begin{array}{l}\text { Em um conjunto infinito de problemas, aqueles que são considerados mais apropriados para tratamento das autoridades públicas são os que } \\
\text { interessam aos analistas das políticas públicas (Frey, 2000). Nesse sentido, os problemas que são reconhecidos pelos formuladores de políticas } \\
\text { como legítimos passam a pertencer à agenda de governo (Theodoulou, 1995). }\end{array}$ \\
\hline Definição de agenda & $\begin{array}{l}\text { Viana (1996) define agenda como um conjunto de temas ou problemas que são percebidos pelo governo como merecedores de intervenç̃o. } \\
\text { Conforme Saravia (2006), um problema só é inserido na agenda se ele justificar uma intervenção pública, sob a forma de decisão das } \\
\text { autoridades públicas. }\end{array}$ \\
\hline Formulação & $\begin{array}{l}\text { Nesta etapa, são elaborados métodos, programas, estratégias e/ou aç̃os que poderão ser utilizadas para o alcance dos objetivos estabelecidos } \\
\text { (Secchi, 2010). Nesse sentido, Jann \& Wegrich (2007) destacam que, durante a formulação de políticas, os problemas, as propostas e as } \\
\text { demandas são transformados em programas de governo. }\end{array}$ \\
\hline Implementação & $\begin{array}{l}\text { Rua (1997) compreende a implementação como um conjunto de accões a serem realizadas por grupos ou indivíduos, direcionadas para } 0 \\
\text { alcance dos objetivos estabelecidos. Esta fase possui como finalidade colocar em prática as políticas públicas elaboradas (Frey, 2000). }\end{array}$ \\
\hline Avaliação & $\begin{array}{l}\text { A avaliação compreende o processo de medição sistemática da operaç̃ão e/ou dos resultados de um projeto, programa ou política, em relação } \\
\text { ao desempenho, eficácia e impacto (ambos esperados ou não), tendo em vista os objetivos predeterminados (implííitos ou explíitos) como } \\
\text { forma de contribuir para o aprimoramento das ações (Rossi et al., 2004; Morra-Imas \& Rist, 2009). }\end{array}$ \\
\hline
\end{tabular}

Fonte: Elaboração própria com base nos autores citados.

Quadro 2 - Características observadas para traçar perfil metodológico dos artigos

\begin{tabular}{|c|c|c|}
\hline $\begin{array}{c}\text { Característica } \\
\text { observada }\end{array}$ & & Descrição \\
\hline \multirow[t]{3}{*}{ 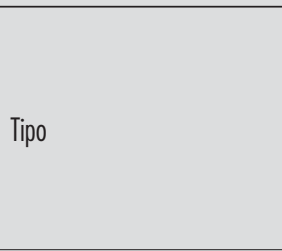 } & Artigo teórico & $\begin{array}{l}\text { Estudos que não envolvem teste empírico e que se limitam a conceitos, proposições, identificação de variáveis, } \\
\text { construção de modelos (Morais et al., 2013). }\end{array}$ \\
\hline & Empírico & $\begin{array}{l}\text { Estudos em que não há um quadro referencial espećifico para interpretação da realidade, concentrando-se } \\
\text { apenas na observação e na análise de dados (Morais et al., 2013). }\end{array}$ \\
\hline & Teórico-empírico & $\begin{array}{l}\text { Estudos que partem de um referencial teórico e que, após a coleta de dados, buscam confirmá-lo ou refutá-lo de } \\
\text { forma total ou parcial (Morais et al., 2013). }\end{array}$ \\
\hline \multirow{3}{*}{ Abordagem } & Quantitativo & $\begin{array}{l}\text { Estudos que empregam a quantificação tanto na coleta quanto análise dos dados (Richardson, 1999), fazendo } \\
\text { uso de procedimentos estatísticos mais ou menos robustos. }\end{array}$ \\
\hline & Qualitativa & $\begin{array}{l}\text { Pesquisa que compreende um conjunto de técnicas interpretativas com o intuito de descrever e decodificar os } \\
\text { componentes de um sistema complexo de significados (Neves, 1996), isto é, traduzir e expressar o sentido dos } \\
\text { fenômenos do mundo social (Maanen, 1979). }\end{array}$ \\
\hline & Misto (quali-quanti) & Pesquisas que se valem de ambas as abordagens (quantitativa ou qualitativa) para desenvolver o estudo. \\
\hline \multirow{2}{*}{ Estratégias de pesquisa } & Coleta de dados & Conjunto de técnicas utilizadas para coleta dos dados. \\
\hline & Análise dos dados & Conjunto de técnicas utilizadas para análise e interpretação dos dados coletados. \\
\hline
\end{tabular}

Fonte: Elaborado pelos autores com base nos autores citados. 


\section{Resultados e interpretações}

A seção de resultados está estruturada de acordo com as categorias estabelecidas nos procedimentos metodológicos: o perfil da publicação, o foco, a temática, as etapas do ciclo de políticas públicas e, por fim, o perfil metodológico.

\section{Perfil da publicação}

A primeira dimensão observada para delinear o perfil da publicação foi o periódico em que os textos relacionados a políticas públicas e habitação foram publicados. Tais informações (Tabela 1) mostram que a revista Ambiente Construído (AC) é a que mais possui artigos publicados, seguida pela Revista de Administração Pública (RAP).

É interessante notar o panorama diversificado dos perfis dos periódicos identificados, uma vez que: a revista $\mathrm{AC}$ direciona-se à área de tecnologia do ambiente construído, com intuito de promover artifícios para tanto; a RAP direciona-se à gestão e sua prática no âmbito da administração pública; o Caderno CRH visa fomentar discussões que envolvam a construção do pensamento crítico nas Ciências Sociais; a URBE, por sua vez, centra-se em estudos urbanos, com leque abrangente a pesquisas que envolvam o planejamento urbano e regional, arquitetura e urbanismo, gestão e administração pública, políticas públicas, além de geografia, infraestruturas e tecnologias urbanas e do meio ambiente. Percebe-se, com isso, a multidisciplinariedade de áreas das Ciências Sociais Aplicadas (Administração, Economia, Arquitetura e Urbanismo, Sociologia) que envolve essa temática. Isso nos lança luz para a possibilidade de as discussões serem analisadas por diversas lentes (teóricas, conceituais e técnicas), na tentativa de compreender a relação da habitação com as políticas públicas.

Outro elemento analisado diz respeito aos autores dos estudos. Carlos Torres Formoso foi o pesquisador com maior frequência de trabalhos publicados, enquanto que os que aparecem com a segunda maior participação obtiveram o mesmo número de observações. Esses resultados podem ser vistos na Tabela 2 .

É válido ressaltar que os três pesquisadores mais recorrentes na produção científica analisada são profissionais que atuam na Universidade Federal do Rio Grande do Sul (UFRGS). Isso nos permitiu identificar
Tabela 1 - Periódicos

\begin{tabular}{lcc}
\hline \multicolumn{1}{c}{ Periódicos } & Frequência & Percentual \\
\hline Ambiente Construído (AC) & 10 & $26 \%$ \\
Revista de Administração Pública (RAP) & 08 & $21 \%$ \\
Caderno CRH & 06 & $16 \%$ \\
$\begin{array}{l}\text { Revista Brasileira de Gestão Urbana } \\
\text { (URBE) }\end{array}$ & 04 & $11 \%$ \\
Demais periódicos* & 10 & $26 \%$ \\
Total & $\mathbf{3 8}$ & $\mathbf{1 0 0 \%}$
\end{tabular}

*Representam as revistas que obtiveram frequência única de participação na distribuição de artigos analisados.

Fonte: Resultados da pesquisa.

Tabela 2 - Principais autores

\begin{tabular}{lcc}
\hline \multicolumn{1}{c}{ Autores } & Frequência & Percentual \\
\hline Carlos Torres Formoso & 04 & $5 \%$ \\
Antônio Tarcísio da Luz Reis & 02 & $2 \%$ \\
Márcia Elisa Soares Echeveste & 02 & $2 \%$ \\
Demais autores* & 78 & $91 \%$ \\
Total & $\mathbf{8 9}$ & $\mathbf{1 0 0 \%}$ \\
\hline
\end{tabular}

*Representam os pesquisadores que obtiveram frequência única de participação na distribuiç̃ão de artigos analisados.

Fonte: Resultados da pesquisa.

uma rede (Figura 3) devido às associações entre eles e outros pesquisadores - todos da mesma instituição -, embora os não citados na Tabela 2 apareçam uma única vez nos estudos pesquisados.

Os resultados obtidos ao analisar os autores reforçam as informações trazidas pela dimensão instituição, na Tabela 3. A UFRGS foi a que registrou maior número de autores filiados.

A difusão é um aspecto interessante ao observar os estudos analisados. A Universidade de São Paulo (USP) abarca o segundo maior número de pesquisas, sem, entretanto, identificar cooperação entre os envolvidos na produção. Isso também pode ser percebido nas demais instituições. Uma possível explicação advém do caráter multidisciplinar que a temática admite, ou seja, pesquisadores da mesma instituição, mas de departamentos diferentes, podem produzir estudos isolados que envolvam o mesmo objeto. 
Tabela 3 - Instituiç̃ões

\begin{tabular}{|c|c|c|}
\hline Instituição & Frequência & Percentual \\
\hline $\begin{array}{l}\text { Universidade Federal do Rio Grande do } \\
\text { Sul (UFRGS) }\end{array}$ & 06 & $16 \%$ \\
\hline Universidade de São Paulo (USP) & 05 & $14 \%$ \\
\hline Universidade Federal de Viçcosa (UFV) & 02 & $5 \%$ \\
\hline $\begin{array}{l}\text { Universidade Federal de Minas Gerais } \\
\text { (UFMG) }\end{array}$ & 02 & $5 \%$ \\
\hline $\begin{array}{l}\text { Universidade Estadual de Campinas } \\
\text { (UNICAMP) }\end{array}$ & 02 & $5 \%$ \\
\hline $\begin{array}{l}\text { Pontifícia Universidade Católica de } \\
\text { Campinas (PUC-Campinas) }\end{array}$ & 02 & $5 \%$ \\
\hline Demais instituiçōes* ${ }^{\star}$ & 19 & $50 \%$ \\
\hline Total & 38 & $100 \%$ \\
\hline
\end{tabular}

*Representam as instituições que obtiveram frequência única de participação na distribuição de artigos analisados.

Fonte: Resultados da pesquisa.

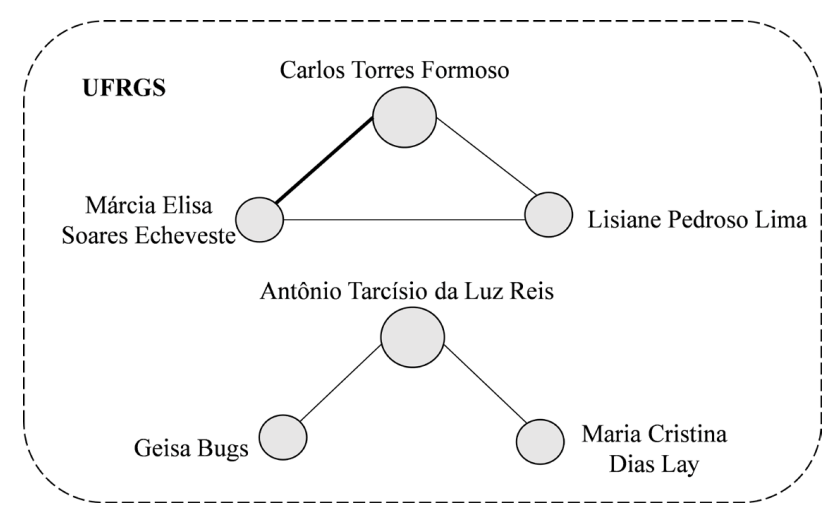

Figura 3 - Rede de cooperação de pesquisadores da UFRGS Fonte: Elaborada pelos autores.

Nota: A linha mais espessa que conecta os integrantes da rede indica maior número de relações do que a linha menos espessa. A circunferência maior revela que o pesquisador tem mais produção no âmbito da rede.

Quanto ao ano das publicações (Tabela 4), a proposta foi verificar a produção científica nos três momentos peculiares da trajetória da política habitacional. Todavia, para o período que compreende os anos de 1964 a 1986 e 1987 a 1999 - as épocas mais antigas no horizonte temporal analisado -, foram encontrados poucos estudos.

Nota-se, no entanto, a concentração dos estudos no período pós-2000, com destaque a partir do ano de 2010. Essa maior produção pode ser explicada
Tabela 4 - Ano das publicações

\begin{tabular}{|c|c|c|c|}
\hline Ano & Período & Frequência & Percentual \\
\hline 1977 & 1964 a 1986 & 02 & $5,3 \%$ \\
\hline 1988 & \multirow{2}{*}{1987 a 1999} & 02 & \multirow{2}{*}{$7,9 \%$} \\
\hline 1997 & & 01 & \\
\hline 2001 & \multirow{10}{*}{2000 a 2014} & 01 & \multirow{10}{*}{$86,8 \%$} \\
\hline 2003 & & 01 & \\
\hline 2006 & & 01 & \\
\hline 2007 & & 01 & \\
\hline 2009 & & 01 & \\
\hline 2010 & & 03 & \\
\hline 2011 & & 07 & \\
\hline 2012 & & 04 & \\
\hline 2013 & & 03 & \\
\hline 2014 & & 11 & \\
\hline Total & - & 38 & $100 \%$ \\
\hline
\end{tabular}

Fonte: Resultados da pesquisa.

devido ao aumento das intervenções governamentais no setor habitacional, materializada com a criação de programas, expansão das linhas de atuação e de fontes de recursos financeiros.

Adicionalmente, o fato de ter ocorrido essa concentração em relação às publicações também pode ter uma de suas vertentes explicada pelo advento da maioria dos periódicos analisados ter ocorrido a partir do fim da década de 1980 e ao longo da década de 1990. Antecedendo esse período, os meios mais comuns para divulgação dos estudos científicos ocorriam por meio de livros que, como evidenciado, não foram considerados para a realização do estudo.

Ao analisar a abrangência das pesquisas, percebeu-se que os estudos focalizaram suas atenções em nível local, isto é, nas municipalidades. Considerando as pesquisas que envolviam análises em âmbito nacional, evidencia-se que apresentaram a segunda maior frequência (Tabela 5).

Ao considerar que a maioria dos estudos foi realizada em âmbito subnacionais, optou-se por fazer um mapeamento estadual da produção científica, o que está ilustrado na Figura 4.

Pode-se visualizar que os Estados de São Paulo e do Rio Grande do Sul são aqueles que obtiveram maior número de estudos envolvendo as realidades 


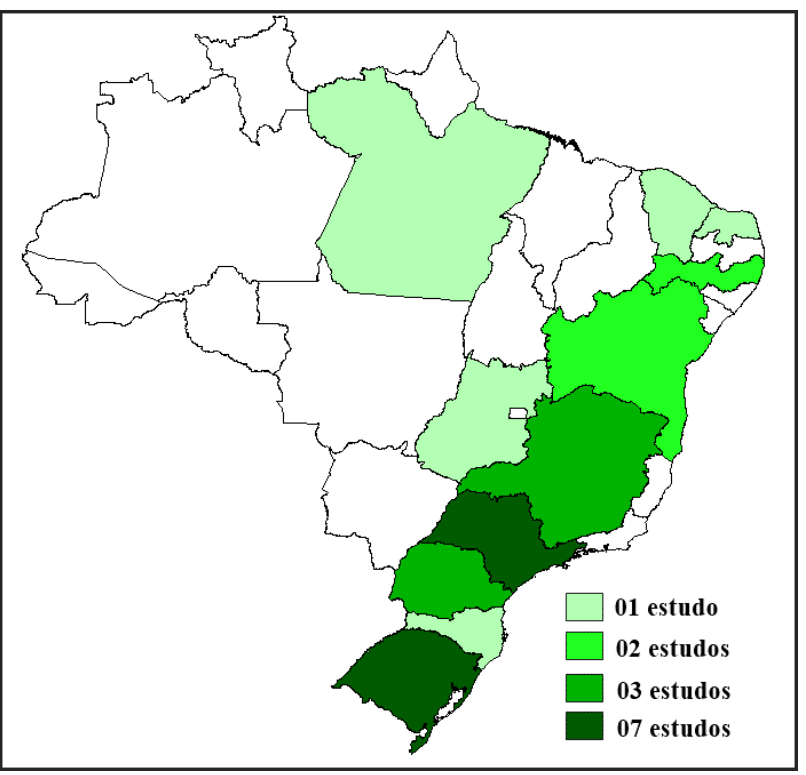

Figura 4 - Mapeamento estadual da produção

Fonte: Elaborado pelos autores.

municipais, regionais ou estaduais. Esse delineamento corrobora o fato de as pesquisas serem produzidas por pesquisadores vinculados a instituições como a UFRGS e a USP.

\section{Foco}

Buscando identificar os principais objetos de estudo das publicações analisadas, destacou-se o foco das pesquisas. Nessa categoria, foi abordada a dimensão do objeto, isto é, se correspondeu à investigação sobre a política ou um programa específico.

Com essa apreciação, identificou-se como a produção científica buscou compreender a habitação, seja por meio das políticas e suas complexidades ou análises mais específicas que buscam melhor detalhamento e, possivelmente, aperfeiçoamento de programas públicos e sociais.

O foco das pesquisas esteve concentrado nos programas e na política nacional, como pode ser visualizado na Tabela 6. Destaca-se que não foram todos os estudos que apresentavam considerações sobre o âmbito nacional. Foi perceptível que as discussões giravam em torno das determinações federais (tanto em termos de política, programas e projetos), mas o espaço de análise era subnacional. Isso fica mais evidente nos estudos que analisavam os
Tabela 5 - Âmbito de realização dos estudos

\begin{tabular}{lcc}
\hline \multicolumn{1}{c}{ Âmbito } & Frequência & Percentual \\
\hline Municipal & 21 & $55 \%$ \\
Nacional & 09 & $24 \%$ \\
Estadual & 05 & $13 \%$ \\
Regĩão Metropolitana & 03 & $8 \%$ \\
Total & $\mathbf{3 8}$ & $\mathbf{1 0 0 \%}$ \\
\hline
\end{tabular}

Fonte: Resultados da pesquisa.

Tabela 6 - Foco dos estudos

\begin{tabular}{lcc}
\hline \multicolumn{1}{c}{ Foco } & Frequência & Porcentagem \\
\hline Programa nacional & 12 & $32 \%$ \\
Pollitica nacional & 11 & $29 \%$ \\
Pollitica municipal & 09 & $24 \%$ \\
Programa municipal & 03 & $8 \%$ \\
Pollitica estadual & 02 & $5 \%$ \\
Programa estadual & 01 & $3 \%$ \\
Total & $\mathbf{3 8}$ & $\mathbf{1 0 0 \%}$ \\
\hline
\end{tabular}

Fonte: Resultados da pesquisa.

programas nacionais, tendo em vista que as ações do governo em relação à questão habitacional ocorrem de maneira descentralizada. É em esfera local que os programas nacionais, derivados de suas políticas, materializam-se.

Por terem maior volume de recursos aportados e, por consequência, maior evidência e abrangência, os estudos relacionados às políticas e programas do governo federal concentram considerável volume em relação à produção científica, o que pode representar um indicativo de que a abrangência da atuação da política ou programa possui influência em relação à produção científica voltada para habitação.

\section{Temática}

No que se refere à temática, buscou-se verificar quais os principais assuntos discutidos nas publicações, ou seja, compreender quais os direcionamentos da produção científica envolvendo habitação e políticas públicas. Nessa perspectiva, com base na Tabela 7, foi 
Tabela 7 - Temática dos estudos

\begin{tabular}{lcc}
\hline \multicolumn{1}{c}{ Tema } & Frequência & Percentual \\
\hline Projetos de EHIS & 09 & $24 \%$ \\
Aluguel social & 06 & $16 \%$ \\
Gestão urbana e ambiental & 06 & $16 \%$ \\
Participação social & 05 & $13 \%$ \\
Financiamento habitacional & 04 & $11 \%$ \\
Desempenho & 02 & $5 \%$ \\
Demais temas & 06 & $16 \%$ \\
Total $^{*}$ & $\mathbf{3 8}$ & $\mathbf{1 0 0 \%}$ \\
\hline
\end{tabular}

*Representam os temas que obtiveram frequência única de participaç̃ão na distribuição de artigos analisados.

Fonte: Resultados da pesquisa.

possível elencar seis principais temáticas: projetos de Empreendimentos de Habitação de Interesse Social (EHIS); aluguel social; gestão urbana e ambiental; participação social; financiamento habitacional; desempenho.

A temática com maior destaque, "projetos de EHIS", apresentou variado conjunto de subtemas, que compreendiam proposições de modelos ou a própria avaliação técnica de empreendimentos, além de relacionar questões como o mercado imobiliário e sua relação com a localização desses empreendimentos. Devido à necessidade de nível de detalhamento em relação a esses projetos, percebeu-se que, em sua maioria, as publicações tiveram como abrangência de análise programas nacionais implementados em municípios específicos.

Em relação ao tema "aluguel social", identificaram-se estudos que abordaram o assunto como um problema social (no sentido do comprometimento da renda familiar e a relação com o mercado imobiliário) e por meio da realização de avaliações de programas direcionados a essa modalidade. Percebeu-se que a abrangência espacial dos estudos foi municipal, fato que pode ser explicado pela baixa disponibilidade de programas com essas características tanto em âmbito nacional quanto estadual.

Os estudos aglutinados sob a temática "gestão urbana e ambiental" apresentaram maior dispersão em relação aos seus subtemas, tendo em vista o maior volume de variáveis que são influenciadas pelo assunto destacado. Assim, foram identificadas: situações problemáticas (precariedade habitacional no país, segregação urbana e impactos ambientais); questões referentes a sistemas de financiamento, programas e demais instrumentos que contribuem para a gestão urbana; discussões acerca do direito e a questão habitacional.

Abordagem com crescente evidência nos últimos anos, a "participação social", como temática na produção científica em habitação, tem na avaliação de políticas públicas seu principal direcionamento. Convém ressaltar que os artigos enquadrados nesse quesito tinham ano de publicação posterior a 2010, demonstrando seu caráter de novidade em relação ao debate na questão habitacional. Desse modo, notou-se que os estudos buscaram analisar programas (em âmbito estadual e municipal) sob a perspectiva dos beneficiários. As análises foram realizadas no segmento da Habitação de Interesse Social (HIS), ou seja, no grupo que engloba famílias com baixo rendimento monetário.

0 quinto assunto abordado refere-se ao "financiamento habitacional", no qual foram percebidas produções, predominantemente avaliativas, referentes aos investimentos governamentais realizados e sobre o fenômeno da inadimplência. Assim como a temática anterior, a de "desempenho" agrupa estudos avaliativos que abordam situações locais.

\section{Etapas do ciclo de políticas públicas}

As etapas do ciclo de políticas públicas foram abordadas na pesquisa como forma de verificar sob qual(is) etapa(s) predominam os estudos analisados. Assim sendo, como resultados, percebeu-se a maior concentração de artigos com caráter avaliativo, fato que caracteriza a produção científica sobre a habitação no país.

Os estudos que se propunham a analisar mais de uma etapa do modelo em destaque foram agrupados na categoria "ciclo de políticas públicas", apresentando a segunda maior frequência de trabalhos. Em seguida, encontram-se os estudos voltados para a "percepção do problema”, "formulação de políticas" e "implementação". Um ponto que pode ser considerado deficitário é o fato de não terem sido encontrados estudos que versavam quanto à etapa de "definição de agenda", fato que indica uma lacuna na produção científica (Tabela 8). 
Quase que em sua totalidade dos artigos que possuíam uma abordagem avaliativa (16 em 20) tinha como território de abrangência os municípios. Tal achado é resultante da temática envolvida nesses estudos, tendo em vista que buscaram avaliar projetos para EHIS, processos de pós-ocupação e programas municipais com a modalidade de aluguel social. Essas temáticas de avaliação exigem maior grau de detalhamento e possuem elevado custo, fatos que podem explicar esse comportamento.

Os artigos que compilaram mais de uma etapa do ciclo de políticas públicas abordaram temas diversos, em âmbito nacional e municipal. Assim, foram encontrados estudos referentes à gestão urbana e ambiental, à participação social no contexto da habitação, à relação dos modelos de administração pública com a política habitacional, além de modalidades de programas como o aluguel social.

Tabela 8 - Âmbito de realização dos estudos

\begin{tabular}{lcc}
\hline $\begin{array}{l}\text { Etapa do ciclo de } \\
\text { políticas públicas }\end{array}$ & Frequência & Percentual \\
\hline Avaliação & 20 & $53 \%$ \\
Ciclo de políiticas públicas & 07 & $18 \%$ \\
Percepção do problema & 06 & $16 \%$ \\
Formulação de políticas & 03 & $8 \%$ \\
Implementação & 02 & $5 \%$ \\
Definiç̦ão de agenda & 00 & $0 \%$ \\
Total & $\mathbf{3 8}$ & $\mathbf{1 0 0 \%}$ \\
\hline
\end{tabular}

Fonte: Resultados da pesquisa.
Em relação à fase de "formulação de políticas", destaca-se que os estudos são relativamente novos (entre 2010 e 2011), evidenciando uma área que ainda pode ser mais explorada pelos pesquisadores da área. Instrumentos voltados à gestão urbana, como os Planos Diretores e Planos Locais de Habitação de Interesse Social (PLHIS), representam um fértil território para debates e análises.

Importante eixo para o alcance dos objetivos das políticas públicas, a implementação ainda parece ser o elo perdido, como foi destacado por Hargrove (1975), uma vez que foram encontrados somente dois estudos, datados do ano de 2011. Tais pesquisas abordaram questões relativas aos projetos dos empreendimentos e a participação do cidadão nessa etapa do policy cycle.

De modo geral, a avaliação de políticas e de programas foi o principal campo de análises dos pesquisadores. A maioria (80\%) dos estudos foi publicada entre os anos de 2010 e 2014, estimulada pela Política Nacional de Habitação, com surgimento de grandes iniciativas habitacionais como o Programa Minha Casa, Minha Vida, no ano de 2009.

\section{Perfil metodológico}

O perfil metodológico é a categoria que visa delinear os aspectos da tipologia, da abordagem e das técnicas para operacionalização dos estudos. Como forma de possibilitar melhor visualização dos resultados, os elementos da categoria foram divididos nas Tabelas 9 e 10 .

Na Tabela 9, apresentam-se as informações sobre a tipologia do texto e a abordagem adotada. Nota-se que mais de $70 \%$ da produção envolve o binômio

Tabela 9 - Perfil metodológico I

\begin{tabular}{|c|c|c|c|}
\hline \multirow{2}{*}{$\begin{array}{c}\text { Característica } \\
\text { observada }\end{array}$} & \multicolumn{3}{|c|}{ Descrição } \\
\hline & Elementos & Frequência & Percentual \\
\hline \multirow{4}{*}{ Tipo } & Teórico-empíricos & 27 & $71 \%$ \\
\hline & Empíricos & 09 & $24 \%$ \\
\hline & Artigos teóricos & 02 & $5 \%$ \\
\hline & Total & 38 & $100 \%$ \\
\hline \multirow{4}{*}{ Abordagem } & Qualitativo & 16 & $42 \%$ \\
\hline & Quantitativo & 12 & $32 \%$ \\
\hline & Misto (Quali-quanti) & 10 & $26 \%$ \\
\hline & Total & 38 & $100 \%$ \\
\hline
\end{tabular}

Fonte: Resultados da pesquisa. 
Tabela 10 - Perfil metodológico II

\begin{tabular}{|c|c|c|c|}
\hline \multirow{2}{*}{ Estratégia de pesquisa } & \multicolumn{3}{|c|}{ Descrição } \\
\hline & Técnicas & Frequência & Percentual \\
\hline \multirow{8}{*}{ Coleta de dados } & Pesquisa documental & 21 & $30 \%$ \\
\hline & Levantamento de dados secundários & 13 & $19 \%$ \\
\hline & Entrevista & 13 & $19 \%$ \\
\hline & Questionário & 07 & $10 \%$ \\
\hline & Dados visuais & 06 & $9 \%$ \\
\hline & Observação & 05 & $7 \%$ \\
\hline & Pesquisa bibliográfica & 04 & $6 \%$ \\
\hline & Total & 69 & $100 \%$ \\
\hline \multirow{6}{*}{ Análise de dados } & Análise documental & 24 & $41 \%$ \\
\hline & Estatística descritiva & 15 & $26 \%$ \\
\hline & Análise de conteúdo & 09 & $16 \%$ \\
\hline & Regressão & 03 & $5 \%$ \\
\hline & Demais técnicas* & 07 & $12 \%$ \\
\hline & Total & 58 & $100 \%$ \\
\hline
\end{tabular}

*Representam as técnicas que obtiveram frequência única de participação na distribuição de artigos analisados.

Fonte: Resultados da pesquisa.

teoria-empiria, reforçando o caráter prático da temática que relaciona a ação do governo (por meio da promoção de políticas, programas e projetos) e os impactos na população-alvo de tais intervenções. Quanto à abordagem, embora se tenha evidenciado predomínio de estudos qualitativos, as pesquisas quantitativas e mistas apresentaram frequências próximas, o que nos permite inferir que a produção adota diferentes abordagens.

Outro aspecto adotado para esquematizar o perfil metodológico da literatura analisada foi a estratégia de pesquisa para a coleta e análise dos dados, cujos resultados estão dispostos na Tabela 10.

Ao analisar as técnicas de coleta de dados, pôde-se perceber a recorrência a pesquisas documentais, principalmente tendo como fontes de consulta legislações, normativos e especificações técnicas que institucionalizam as atividades referentes à atuação pública na questão habitacional. Outra técnica em evidência é o levantamento de dados secundários, em geral, na base do Instituto Brasileiro de Geografia e Estatística (IBGE), tendo como referência a Pesquisa Nacional por Amostra de Domicílios (PNAD). Foi recorrente também o levantamento de dados nas localidades, tanto em prefeituras ou em nível estadual. Vale ressaltar a busca por informações com a Caixa Econômica Federal, que é responsável pela gestão financeira dos programas habitacionais existentes no país.

As técnicas de levantamento primário, como questionário e entrevistas, somaram $29 \%$ de frequência, o que nos mostra a possibilidade de associar a pesquisa envolvendo a análise de documentos e informações já produzidas com a experiência coletada no campo, isto é, in loco. Tais características remetem aos estudos teórico-empíricos, uma vez que se constrói um referencial analítico e busca-se analisá-lo diante da realidade pesquisada.

Outra técnica que nos chama atenção é a coleta por meio de dados visuais. Por se tratar de uma política pública que atua no provimento ou na reforma de habitações, alguns estudos recorriam a fotografias das casas, de terrenos, assim como mapas, croquis e plantas. Os dados aferidos dessas técnicas auxiliavam na avaliação técnica dos projetos construtivos em comparação com a percepção do usuário das habitações.

De posse dos dados, identificou-se que as principais técnicas de análise adotadas eram a análise documental, 
a estatística descritiva e a análise de conteúdo. Tais procedimentos corroboram as principais formas de coleta de dados (documentos, questionários e entrevistas). É interessante observar o uso de técnicas parcimoniosas, isto é, ferramentas de análise mais simples, de fácil entendimento e que promovem a adequada interpretação das informações coletadas.

\section{Comentários finais}

A análise da produção científica que versa sobre a política habitacional brasileira, na área de Administração e em outros ramos das Ciências Sociais Aplicadas, empreendida no artigo em tela, trouxe curiosas questões e achados pertinentes para os pesquisadores que se dedicam a essa temática.

Foi perceptível o predomínio dos pesquisadores gaúchos e paulistas, pertencentes, principalmente, à UFRGS e USP. Todavia, em relação aos primeiros, identificou-se a cooperação na produção de pesquisas científicas. Essas questões remontam ao aspecto difuso da produção, uma vez identificados diferentes autores de diferentes instituições sem, entretanto, visualizar parcerias internas ou com pesquisadores externos.

Outra característica interessante repousa sobre a possibilidade de estudar o entrelaçamento da habitação com as políticas públicas sobre diversos enfoques. Os estudos configuram-se como um campo plural e multidisciplinar. As temáticas podem abranger diferentes características, tais como: a relação da família beneficiária de um programa com a moradia; a adequação técnica das casas produzidas com as especificações mínimas desejadas; o comportamento e dinâmica do mercado imobiliário e a especulação financeira que giram em seu entorno; a relação entre os decisores, formuladores e demais atores envolvidos no âmbito das políticas; a integração da política habitacional com a gestão urbana, dentre outras.

Devido a essa gama de possibilidades, constatou-se o emprego de pesquisas teórico-empíricas com enfoques tanto quantitativos quanto qualitativos, o que permite compreender os objetos de acordo com suas peculiaridades.

Algumas tendências percebidas foram: pesquisas que envolvem programas habitacionais de abrangência nacional, como o Programa Minha Casa, Minha Vida e o Programa de Arrendamento Residencial, executados em âmbito local. Para essas inciativas, recentes, percebeu-se a convergência de estudos científicos, principalmente os relacionados à avaliação, isto é, medição de resultados, produtos ou impactos causados pelos projetos executados, principalmente, pela administração pública municipal.

Alguns pontos críticos que merecem ser analisados: (i) essa tendência, anteriormente apontada, indica-nos que outros aspectos de políticas e de programas habitacionais têm sido pouco divulgados, como as etapas de agenda, formulação e implementação; (ii) os estudos estão direcionados à provisão habitacional, isto é, à construção de casas, com pouca produção envolvendo outras perspectivas da política de habitação, como a reforma e a regularização de assentamentos; (iii) percebeu-se o predomínio das pesquisas em âmbito urbano, isto é, nota-se a carência de pesquisas que contemplem a habitação e a realidade rural.

As questões aqui levantadas são indicativos para potenciais novos estudos que contribuam para a discussão desse tema de relevância social, o qual vem ganhando destaque nas atuações do governo. Com isso, cabe a nós, integrantes da academia e que estudamos esse vasto campo, socializar nossas pesquisas para, cada vez mais, fomentar o debate acerca da habitação e das políticas públicas.

\section{Referências}

Abreu, M. G. (2012). Habitação de Interesse Social no Brasil: caracterização da produção acadêmica dos programas de pós-graduação de 2006-2010 (Dissertação de mestrado). Universidade Federal do Mato Grosso, Cuiabá.

Arretche, M. T. S. (1996). Desarticulação do BNH e autonomização da política habitacional. In R. B. A. Affonso, \& P. L. B. Silva (Eds.). Descentralização e políticas sociais (p. 107-138). São Paulo: Fundap.

Azevedo, S. (1988). Vinte e dois anos de política de habitação popular (1964-1986): criação, trajetória e extinção do BNH. Revista de Administração Pública, 22(4), 107-119.

Bardin, L. (2009). Análise de conteúdo (5a ed., Vol. 1). Lisboa: Edições 70.

Bonduki, N. (2004). Origens da habitação social no Brasil (4a ed., Vol. 1). São Paulo: Estação Liberdade.

Brito, R. P., \& Berardi, P. C. (2010). Vantagem competitiva na gestão sustentável da cadeia de suprimentos: um metaestudo. Revista de Administração de Empresas, 50(2), 
155-169. Recuperado em 19 de novembro de 2014, de www.scielo.br/pdf/rae/v50n2/03.pdf

Cooper, H. M., \& Lindsay, J. J. (1998). Research synthesis and meta-analysis. In L. Bickman \& D. J. Rog (Eds.), Handbook of applied social research methods (pp. 315-342). Thousand Oaks: Sage Publications.

Dellagnelo, E. H. L., \& Silva, R. C. (2005). Análise de conteúdo e sua aplicação em pesquisas na administração. In M. M. Vieira, \& D. M. Zouain (Orgs.). Pesquisa qualitativa em administração: teoria e prática (p. 97-118). Rio de Janeiro: FGV.

Frey, K. (2000). Políticas públicas: um debate conceitual e reflexões referentes à prática da análise de políticas públicas no Brasil (Vol. 21). Brasília: IPEA.

Hargrove, E. C. (1975). The missing link. Washington: The Urban Institute.

Jann, W., \& Wegrich, K. (2007). The theories of the policy cycle. In F. Fisher, G. J. Miller, \& M. S. Sidney (Eds.). Handbook of policy analysis: theory, politics and methods (p. 43-62). Boca Raton: CRC Press.

Lage, M. L. C., \& Emmendoerfer, M. L. (2010). Congruências e peculiaridades da produção científica em administração sobre assédio moral nas organizações: perspectivas para a gestão pública. In Anais do IV Encontro de Administração Pública e Governança da ANPAD (p. 1-16). Curitiba: ANPAD.

Maanen, J. V. (1979). Reclaiming qualitative methods for organizational research: a preface. Administrative Science Quarterly, 24(4), 520-526. Recuperado em 19 de novembro do 2014, de www.jstor.org/stable/2392358

Maricato, E. (2008). Brasil, cidades: uma alternativa para a crise urbana (3a ed., Vol. 1). Rio de Janeiro: Vozes.

Melo, M. A. C. B. (1993). Anatomia do fracasso: intermediação de interesses e a reforma das políticas sociais na Nova República. Revista de Ciencias Sociales, 36(1), 119-163.

Morais, M. C. A., Valadares, J. L., \& Emmendoerfer, M. L. (2013) Meta-análise da produção científica internacional sobre empreendedorismo no setor público: o que tem sido escrito acerca disso? In Anais do XXXVIII Encontro da ANPAD (p. 1-16). Rio de Janeiro: ANPAD.

Mororó, M. S. M., Lima, W. F. A. B., \& Vasconcelos, T. F. (2012). Arquitetura paramétrica em habitação de interesse social: uma análise da produção científica no Brasil e no exterior. In Anais do Congresso da Sociedade Iberoamericana de Gráfica Digital - SIGRADI. Fortaleza: SIGRADI.
Morra-Imas, L. G., \& Rist, R. C. (2009). The Road to Results: designing and conducting effective development evaluations. Washington: The World Bank. Recuperado em 19 de novembro de 2014, de https://openknowledge.worldbank. org/handle/10986/2699

Nascimento, P., No., \& Moreira, T. A. (2014). Novas equações para antigas incógnitas: a questão habitacional no Brasil sob a ótica da produção acadêmica nacional. Revista Brasileira de Pós-Graduação, 11, 1-27.

Neves, J. L. (1996). Pesquisa qualitativa: características, usos e possibilidades. Cadernos de Pesquisa em Administração, 1(3), 1-5.

Oliveira, W. M. (1996). Perfil analítico-descritivo da pesquisa sobre clima organizacional em instituições de ensino superior: (1970-1995) (Tese de doutorado). Universidade de São Paulo, São Paulo.

Rich, G. A., Bommer, W. H., Mackenzie, S. B., Podsakoff, P. M., \& Johnson, J. L. (1999). Apples and apples or apples and oranges? A meta-analysis of objective and subjective measures of salesperson performance. Journal of Personal Selling \& Sales Management, 19(4), 41-52. Recuperado em 23 de novembro de 2014, de http://www.jstor.org/ stable/40471763

Richardson, R. J. (1999). Pesquisa social: métodos e técnicas (3a ed., Vol. 1). São Paulo: Atlas.

Rossi, P. H., Lipsey, M. W., \& Freeman, H. E. (2004). Evaluation: a systematic approach. Thousand Oaks: Sage.

Rua, M. G. (1997). Análise de políticas públicas: conceitos básicos. Programa de Apoio a Gerência Social no Brasil. Brasília: BID.

Rua, M. G. (2009). Políticas públicas. Florianópolis: Departamento de Ciências da Administração/UFSC; Brasília: CAPES-UAB.

Saravia, E. (2006). Introdução à teoria da política pública. In E. Saravia, \& E. Ferrarezi (Eds.), Políticas públicas (Vol. 2, p. 21-42). Brasília: ENAP.

Secchi, L. (2010). Políticas públicas: conceitos, esquemas de análise, casos práticos. São Paulo: Cengage Learning.

Theodoulou, S. Z. (1995). How public policy is made. In S. Z. Theodoulou, \& M. A. Cahn (Eds.). Public policy: the essential readings (p. 86-96). New Jersey: Prentice Hall.

Triola, M. F. (2005). Introdução à estatística (9a ed., Vol 1). Rio de Janeiro: LTC. 
Viana, L. A. (1996). Abordagens metodológicas em políticas públicas. Revista de Administração Públicas-RAP, 40(2), 5-43.

Wood, T., Jr., \& Chueke, G. V. (2008). Ranking de produção científica em administração de empresas no Brasil. Revista de Administração Mackenzie, 9(4), 10-12. Recuperado em
22 de novembro de 2014, de www.scielo.br/pdf/ram/ v9n4/v9n4a03.pdf

Recebido: Maio 05, 2015

Aprovado: Jul. 10, 2015 